\title{
PARALYSIS OF THE POSTERIOR INTEROSSEOUS NERVE CAUSED BY TUMOUR: BRIEF REPORT
}

\author{
CARL-OLOF WERNER
}

Below the elbow the posterior interosseous nerve passes beneath the extensor carpi radialis brevis muscle and then continues between the superficial and deep parts of the supinator muscle (Fig. 1). The proximal edge of the superficial supinator muscle forms an arch, the arcade of Frohse. After entering the supinator the nerve innervates the extensor carpi ulnaris, the extensors of the fingers and thumb as well as the abductor pollicis longus. The extensor carpi radialis brevis and longus are supplied before the nerve enters the supinator. A tumour located beneath the nerve at the level of the proximal edge of the supinator muscle presses the nerve against the edge, which usually is fibrous.
Material. Since 1974 the author has observed 10 patients with non-traumatic posterior interosseous nerve paralysis. Electrophysiological examination was performed in eight and revealed the location of the nerve lesion in all. Needle biopsy was performed in six patients and was conclusive in four; although inconclusive in the other two, it enabled malignancy to be excluded.

All the patients were operated upon, the lumps being exposed by division of the supinator muscle. Seven of the tumours were lipomas, two were neurofibromas and one a neurilemmoma. All were located posteriorly beneath the posterior interosseous nerve where that nerve entered the supinator muscle. The nerve was pressed

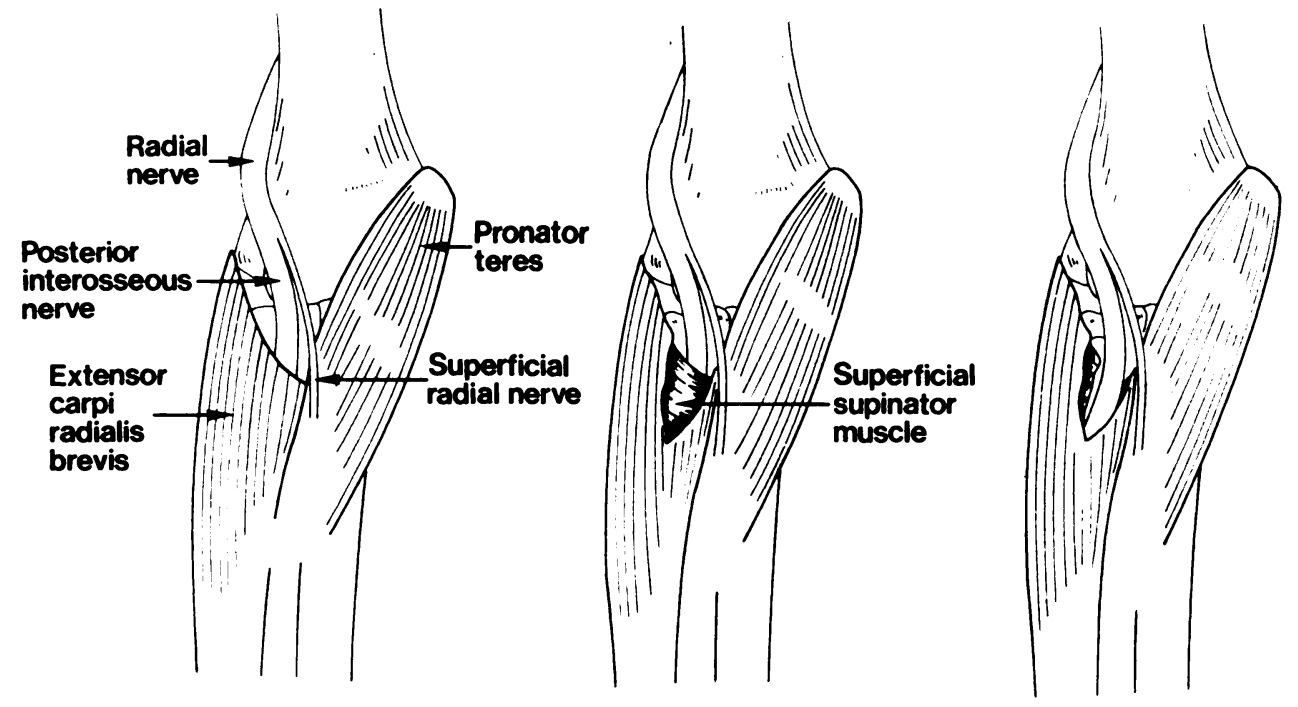

Fig. 1

If the nerve is paralysed, the appearance of the hand is characteristic: extensor carpi ulnaris is paralysed, but not the radial wrist extensors, so the hand deviates radially; and the patient cannot extend the fingers at the metacarpophalangeal joints nor extend or radially abduct the thumb.

Carl-Olof Werner, MD

Department of Orthopaedic Surgery, Hospital of Helsingborg, S-251 87 Helsingborg, Sweden.

(C) 1987 British Editorial Society of Bone and Joint Surgery $0301-620 \times / 87 / 4 R 22 \$ 2.00$ against the edge of the supinator and in most patients the nerve (PIN) showed a marked indentation at this site (Figs 2 and 3, arrows). All seven patients with a lipoma recovered. In the three patients with neurofibromas or a neurilemmoma there was no recovery or it was incomplete.

Discussion. Paralysis of the posterior interosseus nerve may result from rheumatoid arthritis of the elbow, from constriction of the nerve by fibrous bands and from benign tumours; malignant tumours causing paralysis of this nerve have not been reported. Out of 38 benign tumours reported in the literature as causing such paralysis, 28 were lipomas. 


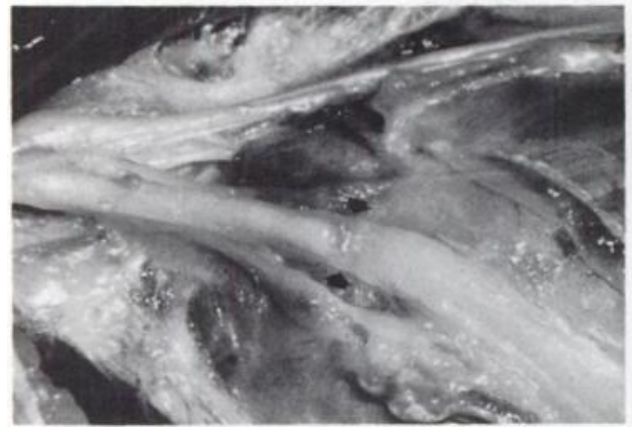

Fig. 2

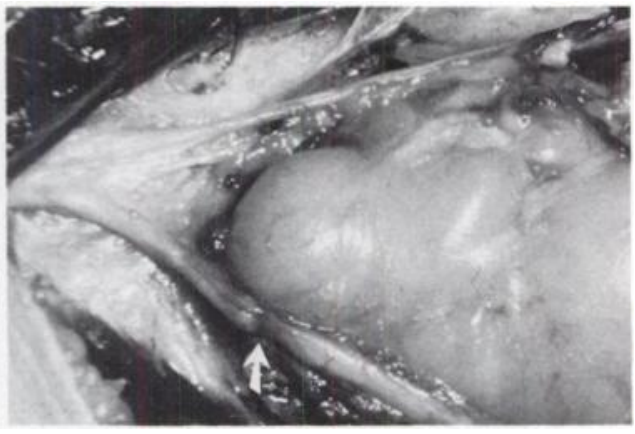

Fig. 3
Needle biopsy is recommended for soft-tissue tumours of the limbs; it may be inconclusive but it nearly always enables malignancy to be excluded (Rydholm 1983). Radiography and CT scanning also may be helpful, but the essential problem is to recognise the possibility that a lipoma may be responsible for the paralysis; otherwise the diagnosis may be missed. One of our patients illustrates this. She had noticed weakness of finger extension for some months and radiographs showed severe cervical spondylosis with narrow intervertebral foramina. She had a great deal of physiotherapy but six months later there was complete paralysis of the finger and thumb extensors and cervical root decompression was considered. Electro-physiological examination, however, showed complete denervation of the posterior interosseous nerve and she was referred for tendon transfers. Only then was the possibility of a tumour considered, and at operation a large lipoma was found and enucleated. Eight months later recovery was complete.

Drawings by the author (reproduced by permission from Acta Orthop Scand 1979, Suppl 174).

\section{REFERENCES}

Rydholm A. Management of patients with soft-tissue tumors: strategy developed at a regional oncology centre. Acta Orthop Scand 1983; Suppl 203.

\title{
THE EFFICACY OF STERILISING ESMARCH BANDAGES: BRIEF REPORT
}

\author{
E. GAINES, R. JOHNSON, M. P. MANNING
}

To minimise tourniquet time for total knee replacement, it has been common practice to prepare and drape the leg before using a "sterile" Esmarch bandage to exsanguinate the limb. The tourniquet is then inflated immediately before the incision is made. We have assessed the sterility of Esmarch bandages after exposing them to a standard autoclaving procedure.

Material and methods. Two lengths of Esmarch bandage

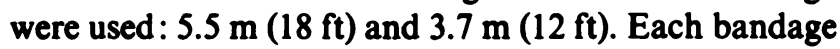
was tested both tightly rolled and loosely folded, and 10 examinations were made of each of the four groups.

\section{E. Gaines, Theatre Technician}

Clatterbridge Hospital, Bebington, Wirral, Merseyside L63 4JY, England.

R. Johnson, MCh Orth, FRCS, Consultant Orthopaedic Surgeon Arrowe Park Hospital, Upton, Wirral, Merseyside L49 5PE, England.

M. P. Manning, FRCS, Orthopaedic Registrar

Royal Liverpool Children's Hospital, Myrtle Street, Liverpool L7 7DG, England.

Correspondence to $\mathrm{Mr} \mathbf{R}$. Johnson.

(C) 1987 British Editorial Society of Bone and Joint Surgery $0301-620 \mathrm{X} / 87 / 4 \mathrm{R} 38 \$ 2.00$
Standard spore strips of Bacillus stearothermophilus were introduced between layers of the bandage. In the rolled group, one strip was placed near the centre of each roll, one near the middle, and one near the outside. In the loosely folded group, the spore strips were placed at the bottom, near the middle, and near the top of each pile.

Finally, a long rolled bandage was tested with two thermocouple leads introduced between the layers, and a third lead was placed in the exhaust port of the autoclave to ensure that the correct sterilising temperature had been reached (DHSS 1980).

The prepared bandages were then subjected to a "porous load" cycle in a Drayton Castle autoclave which conformed to BS 3970 Part 1 (British Standards Institution 1966). This cycle starts with a high vacuum, followed by the introduction of pulsed steam, which ensures rapid heating of the load. The sterilising temperature of $134^{\circ}$ to $136^{\circ} \mathrm{C}$, at 2.3 bars (32 psi) is maintained for three minutes. This is followed by a drying phase and the total cycle time does not exceed 30 minutes. Bacillus stearothermophilus is a thermophilic 